\title{
Assessment of brain dopamine levels to evaluate the role of Tylophora indica ethanolic extract on alcohol induced anxiety in Wistar albino rats
}

\author{
Shyamjith Manikkoth ${ }^{1 *}$, Deepa B ${ }^{2}$, Melinda Sequeira ${ }^{3}$, Anu Elizabeth Joy ${ }^{4}$, Roysten Rodrigues ${ }^{5}$ \\ 1.3 Department of Pharmacology, Yenepoya Medical College, Yenepoya University, Mangalore, INDIA. \\ ${ }^{2}$ Department of Pharmacology, K. S. Hegde Medical Academy, Nitte University, Mangalore, INDIA. \\ ${ }^{4}$ Department of Physiology, Yenepoya Medical College, Yenepoya University, Mangalore, INDIA. \\ ${ }^{5}$ M..B.B.S Intern, Yenepoya Medical College, Yenepoya University, Mangalore, INDIA.
}

\begin{abstract}
Background: Alcohol induced health problems have tormented the world population since time immemorial. This research work was done to study the therapeutic role of Tylophora indica ethanolic extract on alcohol induced anxiety in Wistar albino rats. Method: Wistar albino rats were administered $20 \%$ alcohol, orally twice a day for 30 days. The protective role of Tylophora indica ethanolic extract was evaluated by administering it at a dose of $100 \mathrm{mg} / \mathrm{kg}$ body weight orally in alcohol treated animals for 30 days. Anxiety was assessed by elevated plus maze and light dark arena tests. After that, animals were sacrificed and brains were dissected out, to measure the levels of dopamine. To pinpoint the active constituent responsible for the anxiolytic activity, Tylophora indica ethanolic extract was subjected to HPLC-LCMS analysis. Results: Elevated plus maze and light dark arena tests showed that alcohol induced anxiety can be prevented by Tylophora indica ethanolic extract in Wistar albino rats. There was a significant increase in the levels of Dopamine in the brains of rats, which received Tylophora indica. From the HPLC-LCMS analysis report it is postulated that Tylophorinidine is the active constituent responsible for the anxiolytic activity of Tylophora indica ethanolic extract. Conclusion: Tylophora indica can mitigate the deleterious effect of alcohol in CNS.
\end{abstract}

Key words: Alcohol, Wistar rats, Anxiety, Tylophora indica, Antianxiety, Tylophorinidine.

\section{PICTORIAL ABSTRACT}

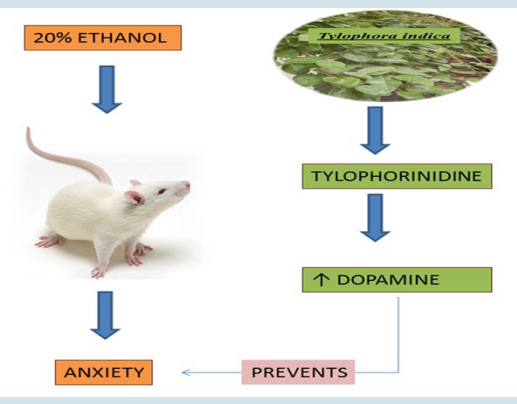

Correspondence :

Dr. Shyamjith Manikkoth,

Department of Pharmacology, Yenepoya Medical College, Yenepoya University, Mangalore, INDIA.

Phone no: 91-0824-2461961

E-mail: shyamjithpubs@gmail.com

DOI: 10.5530/jyp.2016.2.6

\section{INTRODUCTION}

One of the most misused substances by the humans in the world is alcohol, though we are well aware of it sill effects. Alcohol abuse can effect directly or indirectly on the developing and the developed brain with long-lasting complications. Chronic use of alcohol can affect both the central and the peripheral nervous system. Experimental and clinical evidence has confirmed that alcohol impedes with many cellular, neurochemical and molecular events. Research suggests that after chronic alcohol intake, the brain tries to reinstate equilibrium by compensating for the depressant effects of alcohol thereby decreasing brain inhibitory neurotransmission and augments excitatory neurotransmission. This state of excitation is manifested as anxiety. ${ }^{1-5}$

In spite of its potential to cause serious adverse effects, there are no effective drugs to mitigate the deleterious effect of alcohol. In this context the importance of medicinal plants comes to the picture. India has a rich source of various medicinal herbs. As mentioned in Charak Samhitha, many of these plants have wide range of medicinal properties. Medicinal properties of only very few plants have been scientifically proven. ${ }^{6,7}$ Extensive research works have to be carried out to prove the medicinal properties of the unexplored plants and further detailed investigations should be carried out to pinpoint the active constituent of the plant responsible for the proven health benefit.
Tylophora indica is a branching climber found in India. This plant of Asclepiadaceae family is conventionally used for the management of jaundice, inflammation and bronchial asthma. Various parts of this climber have many medicinal uses. Many research works have showed the antiasthmatic, anti-inflammatory, antitumor, anti anxiety, antirheumatic, analgesic, anticonvulsant, hepatoprotective and antioxidant activities of this plant. ${ }^{8-11}$.

The role of Tylophora indica against alcohol induced toxicity has not studied till date, except on alcohol induced hepatic damage. ${ }^{12}$ In this study, the protective role of ethanolic extract of Tylophora indica against alcohol induced anxiety in experimental animal models was evaluated by pharmacological screening methods and biochemical assays.

\section{MATERIALS AND METHODS}

Animals

Six months age old, healthy adult Wistar albino rats (175-200 g), of either sex were used in this study after the Institutional Animal Ethical Committee Clearance (IAEC) approval. The animals were maintained under standard conditions in the animal House. The animals were kept in polypropylene cages and sustained on standard pellet diet, and water ad libitum. 12:12 hour light-dark cycle was maintained. 


\section{Chemicals}

Absolute alcohol (Sigma Aldrich Chemicals, Bangalore)

\section{Plant materials}

\section{Tylophora indica ethanolic extract (TIEE)}

Tylophora indica plants were cultivated. Fresh leaves of Tylophora indica were collected in the month of September. They were authenticated by a botanist. They were shade dried, and then made into coarse powder. A weighed quantity (500 g) of the coarse powder was extracted with ethanol (90\%) in a Soxhlet apparatus. The extract was concentrated on a water bath at a temperature not exceeding $60^{\circ} \mathrm{C}$. The percentage yield of the extract was $6 \%$. The ethanolic extract was suspended in distilled water. It was administered at a dose of $100 \mathrm{mg} / \mathrm{kg}$ body weight orally.

\section{Induction of alcohol toxicity}

$20 \%$ alcohol solution, was prepared using absolute alcohol, and administered twice a day $(1.5 \mathrm{~mL} / 200 \mathrm{~g}$, body weight) at $9.00 \mathrm{am}$ and $5.00 \mathrm{pm}$ for 30 days orally.

\section{Assessment of anxiety}

For studying the effect of the plant extracts on anxiety, the drugs/chemicals were administered orally to Wistar albino rats. The animals were divided into 3 different groups. (Each group consisted of 06 animals, 03 males \& 03 females).

Group I: Normal control (Distilled water).

Group II: Alcohol [20\%]

Group III: Alcohol [20\%]+TIEE [100 mg/kg body weight]

On $30^{\text {th }}$ day, after an hour of drug administration of test compounds, the animals were taken for the following tests for screening their role in anxiety. The tests are as follows;

\section{Elevated plus maze (EPM)}

This test is widely validated to quantify apprehensiveness in rodents. The plus-maze consist three potential anxiogenic factors-novelty, height and open space. The cross-shaped maze consists of four arms that are interconnected by a central platform. Two opposing arms are circumvented by side and culminate-walls (closed arms), whereas the remaining two arms are unprotected (open arms).The set-up consists of a maze of two open arms $(25 \times 5 \mathrm{~cm})$, crossed with walls $(35 \mathrm{~cm}$ high) and central platform $(5 \times 5 \mathrm{~cm})$. The maze is kept $50 \mathrm{~cm}$ above the room floor. The animal is conventionally placed on the central platform, facing one of the closed arms and observed for 5 minutes. During the 5-min test period, the time spent in open and closed arms, was recorded. ${ }^{13-19}$

\section{Light Dark Arena (LDA)}

Light-dark exploration test is one of the few tests concretely designed for use in rats. The maze is divided into two components, $1 / 3$ with opaque walls and a cover (dark compartment) whereas the remaining $2 / 3$ is open and illuminated (light compartment). The door between the two compartments sanctions rat to move from one side to another. Initially the rat is placed in the light compartment and observed for 5 minutes. During that time the time spent in light and dark compartment, was recorded..$^{13-19}$

\section{Estimation of neurotransmitters in Rat brain}

On $30^{\text {th }}$ day, after the pharmacological experiments, animals were euthanized and brain neurotransmitters were estimated using the method described by Habibur Rahman. ${ }^{20}$

\section{Estimation of Dopamine}

On the day of experiment, whole brain was dissected out. Wet tissue was weighed and homogenized in $\mathrm{HCl}$-butanol for about 1 minute (in 1:10 ratio). The sample was then centrifuged for 10 minutes at $3000 \mathrm{rpm}$. An aliquot supernatant phase $(1 \mathrm{ml})$ was removed and added to centrifuge tube containing $2.5 \mathrm{ml}$ hexane and $0.3 \mathrm{ml}$ of $0.1 \mathrm{M} \mathrm{HCl}$. The aqueous phase $(0.2 \mathrm{ml})$ was then taken for dopamine assay. All steps were carried out at $0^{\circ} \mathrm{C}$ (on ice). To the $0.2 \mathrm{ml}$ of aqueous phase, $0.05 \mathrm{ml}$ $0.4 \mathrm{M} \mathrm{HCl}$, and $0.1 \mathrm{ml}$ of Sodium acetate buffer ( $\mathrm{pH} \mathrm{6.9)}$ were added, followed by $0.1 \mathrm{ml}$ iodine solution $(0.1 \mathrm{M}$ in ethanol) for oxidation. The reaction was stopped after $2 \mathrm{~min}$ by addition of $0.1 \mathrm{ml}$ sodium sulphite solution. $0.1 \mathrm{ml}$ acetic acid is added after 1.5 minutes. The solution was then heated to $100^{\circ} \mathrm{C}$ for 6 minutes. When the sample again reached room temperature, excitation and emission spectra were read from the spectrofluorimeter at $330-375 \mathrm{~nm}$. Tissue blanks for dopamine were prepared by adding the reagents of the oxidation step in reversed order (sodium sulphite before iodine).

\section{Calculation}

- The neurotransmitter level is calculated using the following formula.

$$
X_{\text {dopamine }}=\frac{\text { Sample O.D }- \text { Blank O.D }}{\text { Standard O.D - Blank O.D }} \text { X Conc. Of Standard }(500 \mu \mathrm{g} / \mathrm{ml})
$$

This gave the amount of dopamine present in $1 \mathrm{ml}$ of the sample. The final reading of neurotransmitter level is expressed as: $\mu$ moles/g tissue.

\section{Phytochemical analysis of TIEE using HPLC-LCMS analysis.}

HPLC-LCMS analysis (Table 1) was carried out on a Shimadzu UFLC-XR (Ultra-Fast Liquid Chromatography) system which is interfaced to a Mass Spectrometry (Make: AB Sciex, Model: API 4000) instrument at Sequent Laboratories, Mangalore.

\section{Statistical analysis}

Results were expressed as mean $\pm \mathrm{SD}$. One-way analysis of variance (ANOVA) was carried out and the statistical comparisons among the groups were performed with Tukey Krammer test with the help of In Stat -Graph Pad software [Graph Pad software Inc., CA, USA].P value $<0.05$ was considered significant.

\section{RESULTS}

\section{Elevated plus maze}

Results (Table 2) showed that alcohol treated animals (Group II) spent less time in open arm on comparing $(\mathrm{p}<0.001)$ with normal animals (Group I). On the other hand alcohol treated animals which received TIEE simultaneously (Group III) spent more time in open arm of EPM on comparing $(\mathrm{p}<0.001)$ with the alcohol alone treated animals (Group II).

\section{Light Dark Arena}

Results (Table 3) showed that alcohol treated animals (Group II) spent less time in light arena on comparing $(\mathrm{p}<0.001)$ with normal animals (Group I). On the other hand alcohol treated animals which received TIEE simultaneously (Group III) spent more time in light arenaof LDA on comparing $(\mathrm{p}<0.001)$ with the alcohol alone treated animals (Group II). 
MANIKKOTH et al.: Mitigation of alcohol induced anxiety by Tylophora indica in wistar rats

\section{Table 1: Chromatographic conditions}

\begin{tabular}{cc}
\hline Chromatographic conditions & Tylophora indica $^{11}$ \\
\hline Extract & Ethanolic extract \\
Mobile phase & $0.1 \%$ trifluroacetic acid in water: \\
acetonitrile (70:30) & $\mathrm{C}-18$ \\
Column & $30^{\circ} \mathrm{C}$ \\
Column Temperature & $20 \mu \mathrm{L}$ \\
Injection Volume & $0.6 \mathrm{ml} / \mathrm{min}$ \\
Flow rate & $30 \mathrm{~min}$ \\
Run time & $257 \mathrm{~nm}$ \\
Wavelength & Electron Spray Ionization \\
Ion Source & Positive Ionization \\
Mode & $100-1000 \mathrm{amu}$ \\
Mass Scan Range & $5500 \mathrm{~V}$ \\
Ion Spray Voltage &
\end{tabular}

Table 2: Effect of TIEE on the time spend in the arms of Elevated Plus Maze

\begin{tabular}{cccc} 
& Drugs & \multicolumn{2}{c}{ Time spend in each arm in seconds } \\
\cline { 3 - 4 } Group & & Open & Closed \\
\hline I & Distilled water & $8.06 \pm 1.40$ & $252.33 \pm 6.21$ \\
II & Alcohol [20\%] & $1.13 \pm 0.90^{\mathrm{a}}$ & $282.46 \pm 11.53^{\mathrm{a}}$ \\
III & Alcohol [20\%]+TIEE & $50.33 \pm .68^{\mathrm{b}}$ & $162.66 \pm 7.21^{\mathrm{b}}$ \\
\hline
\end{tabular}

One Way ANOVA, followed by Tukey Kramer multiple comparison test

Results were expressed as mean $\pm \mathrm{SD} ; \mathrm{n}=6$.

a: $\mathrm{p}<0.001$ àextremely significant; on comparing group II with group I

$\mathrm{b}$ : $\mathrm{p}<0.001$ àextremely significant; on comparing group III with group II

Table 3: Effect of TIEE onthe time spend in the arena of Light Dark Arena

\begin{tabular}{cccc}
\multirow{2}{*}{ Group } & \multirow{2}{*}{ Drugs } & \multicolumn{2}{c}{$\begin{array}{c}\text { Time spend in each arena in } \\
\text { seconds }\end{array}$} \\
\cline { 3 - 4 } & & Light & Dark \\
\hline I & Distilled water & $30.01 \pm 0.12$ & $250.01 \pm 0.01$ \\
II & Alcohol [20\%] & $3.27 \pm 0.01^{\mathrm{a}}$ & $290.57 \pm 0.05^{\mathrm{a}}$ \\
III & Alcohol [20\%]+TIEE & $42.53 \pm 0.04^{\mathrm{b}}$ & $252.07 \pm 0.14^{\mathrm{b}}$ \\
\hline
\end{tabular}

One Way ANOVA, followed by Tukey Kramer multiple comparison test Results were expressed as mean $\pm \mathrm{SD} ; \mathrm{n}=6$.

a: $p<0.001$ àextremely significant; on comparing group II with group I

b: $p<0.001$ àextremely significant; on comparing group III with group II

Table 4: Brain neurotransmitter levels

\begin{tabular}{cc}
\hline Group & Dopamine (units/g) $\times 10^{3}$ \\
\hline I & $31.14 \pm 1.16$ \\
{$[$ Normal $]$} & $3.283 \pm 0.172^{\mathrm{a}}$ \\
II & \\
{$[$ Alcohol $]$} & $30.655 \pm 0.55^{\mathrm{b}}$ \\
III & \\
{$[$ Alcohol + TIEE] } & \\
\hline
\end{tabular}

One Way ANOVA followed by TukeyKrammer test; $\mathrm{N}=6$

a: $\mathrm{p}<0.001$, considered extremely significant on comparing Group II with Group I

b: $\mathrm{p}<0.001$, considered very significant on comparing Group III with Group II

\section{Table 5: Phytochemical analysis of TIEE using HPLC-LCMS}

\begin{tabular}{cccc}
\hline $\begin{array}{c}\text { Major Peaks with their } \\
\text { Retention time in } \\
\text { minutes }\end{array}$ & $\begin{array}{c}\text { Peak } \\
\text { Area \% }\end{array}$ & $\begin{array}{c}\text { Molecular } \\
\text { Weight } \\
\text { Observed }\end{array}$ & Possible compound \\
\hline 5.79 & 19.325 & 333.9 & $\begin{array}{c}\text { Derivative of } \\
\text { Tylophorinidine } \\
\text { Derivative of } \\
12.90\end{array}$ \\
22.02 & 2.268 & 346.2 & $\begin{array}{c}\text { Tylophorinidine } \\
\text { Tylophorinidine }\end{array}$ \\
\hline
\end{tabular}

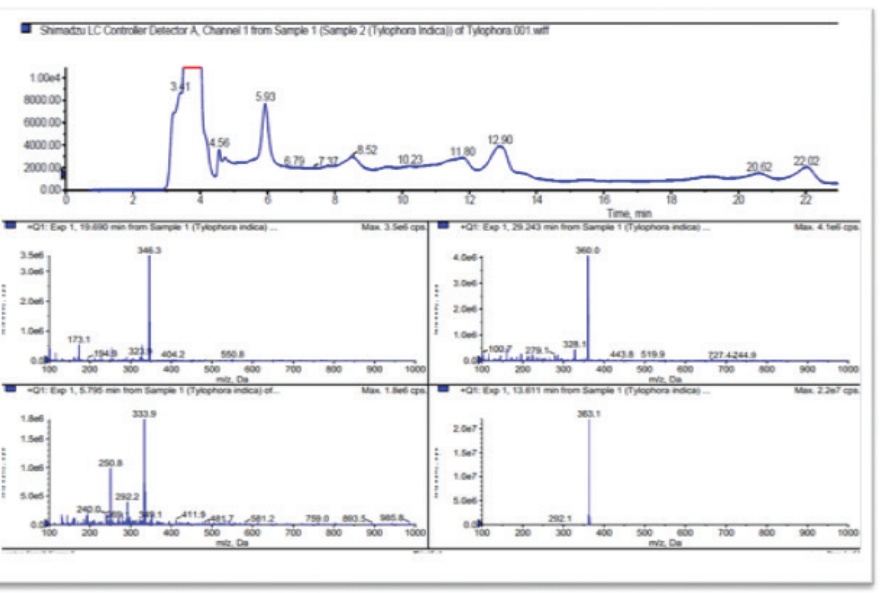

Figure 1: Phytochemical analysis of TIEE using HPLC-LCMS

The findings from (Table 2 and 3 ) clearly show that alcohol exposure can induce anxiogenic behaviour. The anxiogenic potential of alcohol can be mitigated by co-administration of TIEE.

\section{Brain Dopamine levels}

Results (Table 4) showed that dopamine levels in alcohol treated animals (Group II) were significantly less on comparing $(\mathrm{p}<0.001)$ with normal animals (Group I). On the other hand dopamine levels in alcohol treated animals which received TIEE simultaneously (Group III) were significantly increased on comparing $(\mathrm{p}<0.001)$ with the alcohol alone treated animals (Group II).

\section{HPLC analysis of TIEE}

HPLC analysis of TIEE has revealed that major peaks occurred at a retention time of 5.79, 12.90 and 22.02 minutes. When these peaks were subjected to LCMS analysis, the molecular weight of the compounds observed were 333.9, 346.2 and 361.1 (Table 5 and Figure 1). On comparing with the available databases of Tylophora indica, these compounds were identified as derivatives of Tylophorinidine.

\section{DISCUSSION}

Considering the fact that ethanol is the one of the most misused substances in the world, many research works are carried out to establish the deleterious effect of this addictive agent. Studies have clearly indicated that alcohol is neurotoxic. Neurological disorders caused by alcoholism are impaired motor coordination, visual disturbances, cognitive impairment, hallucinations, blackouts, anxiety disorders and seizures. Long term exposure to alcohol alters brain function by interacting with several neurotransmitter systems. Chronic alcohol consumption is associated with several inflammatory and degenerative changes in the central nervous system (CNS) which includes enhanced reactive oxygen species production. ${ }^{1-5,21,22}$ 
In this research work, elevated plus maze and light dark arena results showed that administration of alcohol for 30 days induced anxiety in Wistar albino rats. Studies have reported that under normal conditions there is equilibrium between the inhibitory and excitatory neurotransmitters in the CNS. Short-term exposure to alcohol increases the levels of inhibitory transmitters like GABA and thereby tilting the balance to the inhibitory side. But on continuing exposure to alcohol the brain attempts to tilt the balance towards the excitatory side, by increasing the levels of excitatory transmitters like glutamate. This shift in balance is to compensate for the depressant effect of alcohol. ${ }^{21,22}$ One of the comorbid factors of chronic alcohol use is social anxiety disorder. ${ }^{23}$ Chronic alcohol intake leads to a decrease in the level of striatal dopamine in rats and dopamine $\mathrm{D}_{2}$ receptors in humans..$^{24}$ Neuroimaging studies revealed that reduction in the levels of $\mathrm{D}_{2}$ receptor striatal binding leads to anxiety disorders in humans. ${ }^{25}$ These can be the possible reasons for alcohol induced anxiety. Alcohol induced neurotoxic effect on dopamine is further evidenced by a cohort study, which showed an association with chronic alcohol use and the pre-disposition to Parkinson's disease ${ }^{26}$ and by an animal study, which showed chronic administration of alcohol decreased the brain dopamine levels, thereby leading to neurodegenerative disorder. Current results also confirm, the decrease in levels of dopamine in alcohol treated rats.

The results of the present study as seen in pharmacological tests, showed Tylophora indica ethanolic extract possess significant anxiolytic activity against alcohol induced anxiety. The protective action of Tylophora indica on alcohol induced anxiety can be due to its modulating role on various neurotransmitters or due its antioxidant property.
From the HPLC-LCMS analysis it was found that Tylophorinidine is the active constituent present in the ethanolic extract of Tylophora indica. Tylophorinidine is an alkaloid. ${ }^{11}$ This phytoconstituent is an isoquinoline derivative. ${ }^{27}$ Isoquinoline derived alkaloids are known to inhibit Monoamino oxidase enzyme (MAO) in brain. ${ }^{28}$ It is a known fact that an irreversible MAO inhibitor like Phenelzine, has a proven efficacy against social anxiety disorders. ${ }^{29,30}$ Being an isoquinoline derivative, Tylophorinidine might have increased the levels of monoamines, particularly dopamine (as seen in the result, Table 4), thereby preventing the anxiety induced by alcohol in experimental rats.

This alkaloid also possesses antioxidant activity. ${ }^{11}$ By virtue of this free radical scavenging activity; this compound might have blocked the alcohol induced oxidative damage in the brain, thereby mitigating the anxiogenic effect of alcohol.

\section{CONCLUSION}

Alcohol induced anxiety can be prevented by Tylophorinidine. Further studies are on-goingtofind the exact mechanism by which it acts as neuroprotective agent.

\section{ACKNOWLEDGEMENT}

We Acknowledge the help of Yenepoya Research Centre, Yenepoya University to carry out this research work.

\section{CONFLICT OF INTEREST}

We declare that we have no conflict of interest.

\section{ABBREVIATIONS USED}

TIEE: Tylophora indica ethanolic extract; EPM: Elevated plus maze; LDA: Light Dark Arena; HCI: Hydrochloric acid; M: Molar; O.D: optical density; HPLC-MS: high performance liquid chromatography-mass spectrometry; SD: standard deviation; CNS: Central nervous system; GABA: Gamma amino butyric acid; MAO: Monoamino oxidase.

\section{ABOUT AUTHOR}

Dr. Shyamjith Manikkoth, is an Associate Professor in the department of Pharmacology, Yenepoya Medical College, Yenepoya University, Mangalore. Doing research work mainly in: Medicinal plants and Neuropharmacology.

\section{REFERENCES}

1. Mohan L, Rao USC, Gopalakrishna HN, Nair V. Evaluation of the anxiolytic activity of NR-ANX-C (a Polyherbal Formulation) in ethanol withdrawal-induced anxiety behavior in Rats. Evid Based Complement Alternat Med. 2011;2011:1-7

2. Spanagel R. Alcoholism: a systems approach from molecular physiology to addictive behavior. Physiol Rev. 2009;89(2):649-705.

3. Batman AM, Miles MF. Translating alcohol research: opportunities and challenges. Alcohol Res. 2015;37(1):7-14.

4. Knapp DJ, Overstreet DH, Breese GR. Modulation of ethanol withdrawalinduced anxiety-like behavior during later withdrawals by treatment of early withdrawals with Benzodiazepine/ $\gamma$-aminobutyricacid ligands. Alcohol ClinExp Res. 2005;29(4):553-63

5. Jayaraman T, Kannappan S, Ravichandran MK, Anuradha CV. Impact of Essentiale $\mathrm{L}$ on ethanol induced changes in rat brain and erythrocytes. Singapore Med J. 2008:49(4):320-27.

6. Sheetal $V$, Singh SP. Current and future status of herbal medicines. Vet World. 2008;1(11):347-50.

7. Vaidya ADB, Devasagayam TPA. Current status of herbal drugs in India: an overview. J Clin Biochem Nutr. 2007:41(1):1-11.
8. Shyamjith M, Joy AE, Thyagaraju BM, Rao SN. Effect of Tylophora indica on haloperidol induced catalepsy in experimental animal models. Drug Invention Today. 2012;4(12):652-54.

9. Shyamjith M, Chandrashekar R, Rao SN. Antianxiety activity of Tylophora indica in experimental animal models. Int. J Res Ayur Pharm. 2013;4(1):127-29.

10. Jahas J, Ranjita K, ManikkothS, Rao SN. Protective role of Tylophora indica ethanolic extract on artesunateinduced liver toxicity. Int J Appl Biol Pharm. 2014;5(4):206-10

11. Dhiman M, Naik V, Kshirsagar R, Desai DC, Manju SL. Antioxidant activity of hydrochloride salt of tylophorinidine and tylophorinine isolated from aerial parts of Tylohoraindica. Int J Res Ayur Pharm. 2012;3(1):121-24.

12. Gujrati V, Patel N, Rao VN, Nandakumar K, GoudaTS, Shalam MD, ShantaKumar SM. Hepatoprotective activity of alcoholic and aqueous extracts of leaves of Tylophora indica (Linn.) in rats. Indian J Pharmacol. 2007;39(1):43-7

13. Cryan J, Holmes A. The ascent of mouse: advancesin modelling human depression and anxiety. Nature Rev Drug Discov. 2005;4(9):775-90.

14. Rodgers RJ, Cao BJ, DalviA, Holmes A. Animalmodels of anxiety: an ethological perspective. Braz J Med Biol Res. 1997;30:289-304. 
15. Cryan JF, Sweeney FF. The age of anxiety: role of animal models of anxiolytic action in drug discovery. Br J Pharmacol. 2011;164(4):1129-61.

16. Kalueff $A V$, Tuohimaa P. Experimental modeling of anxiety and depression. Acta Neurobiol Exp. 2004;64(4):439-48.

17. Parasuraman S, Sujithra J, Syamittra B, Yeng WY, Ping WY, Muralidharan S, et al. Evaluation of sub-chronic toxic effects of petroleum ether, a laboratory solvent in Sprague-Dawley rats. J Basic Clin Pharma. 2014;5(4):89-97.

18. Komada M, Takao K, Miyakawa T. Elevated Plus Maze for Mice. J Vis Exp. 2008;22:1088. JoVE. 22. http:// www.jove.com/index/details.stp?id=1088, doi: $10.3791 / 1088$

19. Datusalia AK, Kalra P, Narasimhan B, Sharma S, Goyal RK. Anxiolytic and antiseizure effects of SidatiagiiBhandri. J Health Sci. 2008;54(5):544-50.

20. HabiburRahman, Eswaraiah MC.Simple spectroscopic Methods for estimating Brain Neurotransmitters, Antioxidant Enzymes of Laboratory animals like Mice: A review.Available in http://www.pharmatutor.org/articles/simple-spectroscopicmethod-estimating-brain-neurotransmitter-antioxidnat-enzymes-lab-animals

21. Mukherjee S, Das SK, Vaidyanathan K, Vasudevan DM. Consequences of alcohol consumption on neurotransmitters-an overview. Curr Neurovasc Res 2008;5(4):266-272

22. Valenzuela CF. Alcohol and neurotransmitter interactions. Alcohol Health \& Research World 21. 1997; 144-8.

23. Sarah WB, Carrie LR. Social anxiety disorder and alcohol use. Alcohol Research
\& Health. 2002;26(2):130-35.

24. Panayotis KT, Nora DV, Paul F, Hiroyuki U, Hiroyuki I, George R, et al. Overexpression of dopamine D2 receptors reduces alcohol self-administration. Journal of Neurochemistry 2001;78(5):1094-103.

25. Robinson HM, Hood SD, Bell CJ, Nutt DJ. Dopamine and social anxiety disorder. Rev Bras Psiquiatr. 2006;28(4):263-4.

26. Eriksson AK, Löfving S, Callaghan RC, Allebeck P. Alcohol use disorders and risk ofParkinson's disease: findings from a Swedish national cohort study 1972-2008. BMC Neurology 2013;13(1):190.

27. Ambhore NS, Antony S, Mali JK, Kanhed AM, Bhalerao AR, Bhojraj S. Pharmacological and biochemical interventions ofcigarette smoke, alcohol, and sexual mating frequency on idiopathic rat modelof Parkinson's disease. J Young Pharmacists 2012;4(3):177-83.

28. Tylophorinidine. http://pubchem.ncbi.nlm.nih.gov/compound/161749,Accessed on $12^{\text {th }}$ December 2013

29. Passos CDS, Claudia SP, Amelia H, Muriel C, Pierre-Alain, Philippe C. Alkaloids as inhibitors of monoamine oxidases and their role in the central nervous system. Studies in Natural Products Chemistry. 2014;43:123-43.

30. David S B, Anderson IM, David JN, Borwin B, Bond A, Jonathan RTD. Evidencebased guidelines for the pharmacological treatment of anxiety disorders: recommendations from the British Association for Psychopharmacology. Journal of Psychopharmacology 2005;19(6):567-96. 